\title{
A rare case of carcinoma of the vulva coexisting with third degree uterine prolapse treated in a rural Medical College of West Bengal
}

\author{
Saha DP, Mitra A, Pal R, Nandi JK, Agarwal H, Rani S
}

\begin{abstract}
Coexistence of carcinoma of the vulva and uterovaginal prolapse is very rare. We thus present the simultaneous operative management of the two conditions in a patient with stage II carcinoma of the vulva and third degree uterine prolapse as available literature is very scanty to guide a surgeon.
\end{abstract}

Key words: coexisting, carcinoma vulva, uterovaginal prolapse.

\section{INTRODUCTION}

Carcinoma of the vulva is a relatively uncommon genital malignancy occurring mainly in post-menopausal age group, whereas genital prolapse is a relatively common disorder in this part of the world. However coexistence of these two conditions is very rare and only few cases has been reported ${ }^{1}$. Operative treatment of these two conditions together can pose a few challenges as standardized treatment is not available in literature.

\section{CASE}

We present a case of stage II (T 2 N $0 \mathrm{M} \mathrm{o}$ ) carcinoma of the vulva with longstanding 3rd degree uterine prolapse. Mrs D.D., a 45 year old perimenopausal woman with two children presented at North Bengal Medical College with an itchy lesion in her vulva for six months along with a mass coming out through the vagina for about 10 years. The mass came out gradually after her second childbirth and was partially exposed all the time. She could reduce the mass by herself and had no difficulty in micturition or defecation. However during the last six months before presenting to us she

1 North Bengal Medical College, Sushrutanagar, Siliguri, West Bengal, India.

Correspondence: Dr. Dipta Prasun Saha

E-mail: dipra.saha@gmail.com

Competing interests: None had an itchy lesion in the vulva which grew rather rapidly and there was foul smelling discharge and occasional bleeding.

On examination a $5 \times 4 \mathrm{~cm}$ fungating lesion with areas of necrosis and haemorrhage involving the labia majora and minora and the distal urethra was found. There was no anal and perineal involvement. Third degree uterine prolapse with cystocele and rectocele was also found. The cervix and vagina was apparently healthy. On bimanual examination the uterus was slightly bulky, freely mobile and there was no adnexal mass. Bilateral inguinofemoral lymph nodes were palpable.

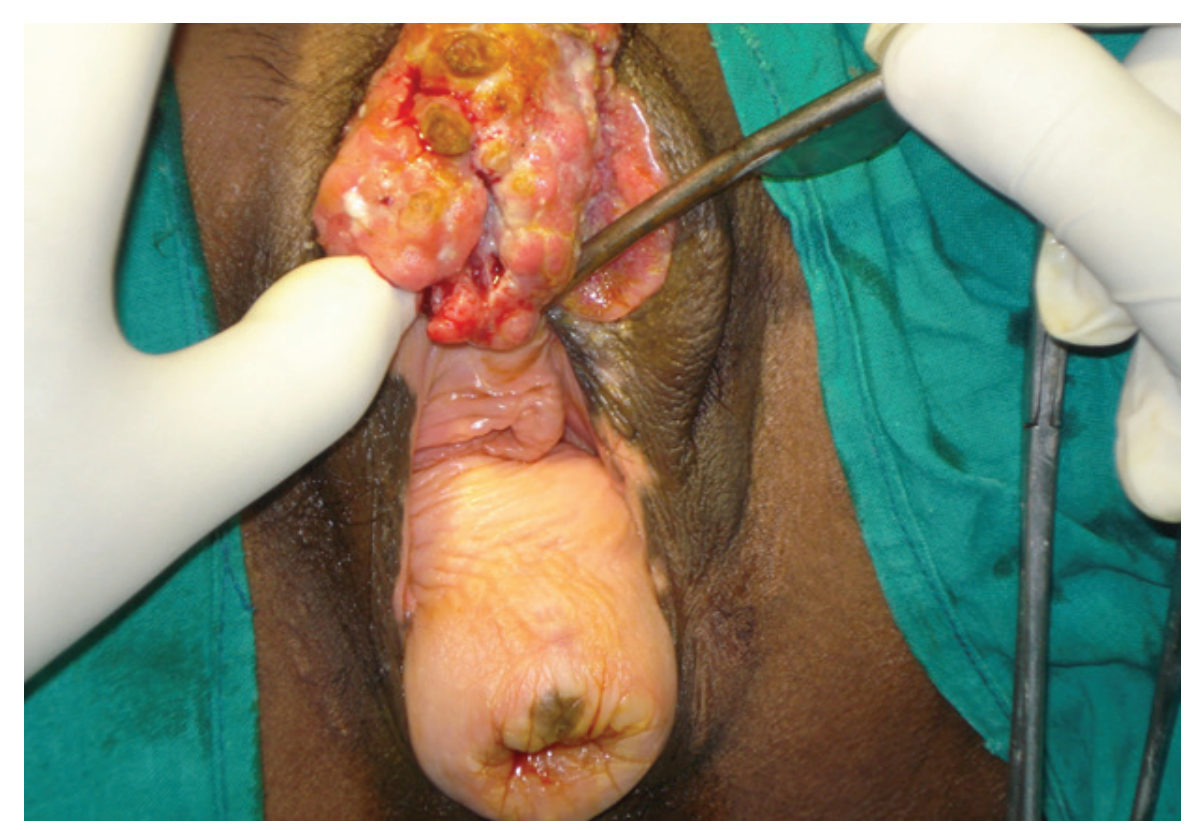

Figure 1: Prolapse with carcinoma vulva (metal catheter in the urethra)
Vulval biopsy confirmed infiltrating squamous cell carcinoma. Cervical Pap smear was normal. Vaginal hysterectomy with pelvic floor repair (VH PFR) was done followed by radical vulvectomy (including excision of the distal urethra) and bilateral inguinofemoral lymph node dissection by separate incisions. The operation was rather prolonged taking about four and half hours and the recovery was uneventful other than infection in the groin wound which healed by secondary intention.

Histopathological examination of the operative specimen showed well differentiated squamous cell carcinoma infiltrating up to the reticular dermis. The three resection margins and the deep resection margin were free of tumour. Lymph nodes showed no evidence of malignancy and showed sinus histiocytes. Uterus showed features of adenomyosis with proliferative endometrium while cervix showed features of nonspecific cervicitis. 


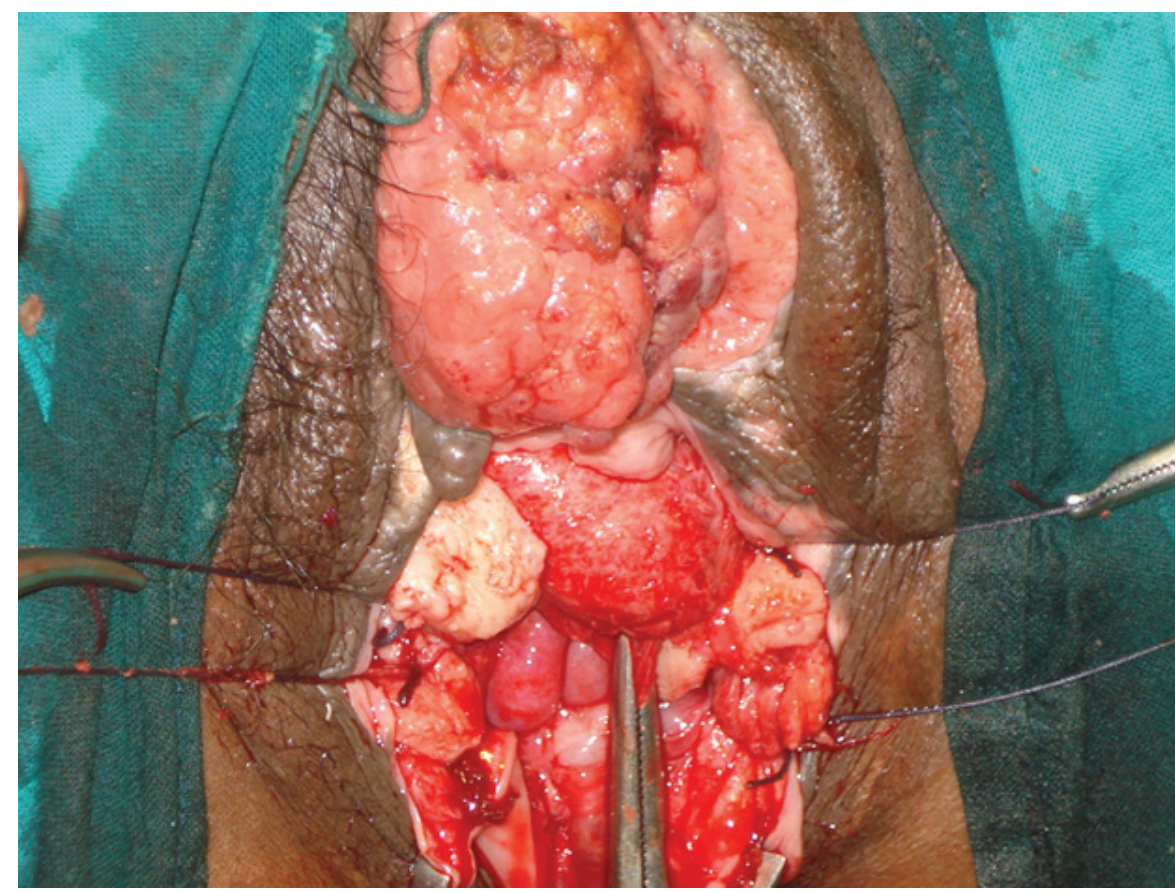

Figure 2: Vaginal hysterectomy stumps prior to radical vulvectomy

Patient received postoperative radiotherapy and now is under follow up without any complaints.

\section{DISCUSSION}

Vulvectomy prior to vaginal However in patients with small hysterectomy would diminish the any uterine prolapse, as in most of the cases we usually find, vulvectomy followed by repair of associated vaginal prolapse with reinforcement or reconstruction of the perineal body has been described ${ }^{2}$.

\section{ACKNOWLEDGMENT}

We acknowledge the help of all doctors including anaesthetists and paramedics who helped us in this prolonged operation.

\section{REFERENCES}

1. Carcinoma of the Vulva with coexistent Genital Prolapse- A contrasting View, In "Clinical Problems, Injuries and Complications of Gynecologic and Obstetric Surgery. Third Edition Ed. by D.H. Nichols and J.O. DeLancey.pp.349353. Williams \&Wilkins. Baltimore.1995

we planned vaginal hysterectomy first followed by vulvectomy. This also ensured there was no additional tension during closure of the vulvectomy incision.

cystocele and/or rectocele without
2. "Malignancies of the vulva" by M.S. Hoffman, in "TeLinde's Operative Gynaecology" Tenth edition Ed. by J.A. Rock and H.W. Jones III pp 1177, Lippincott Williams and Wilkins, Baltimore. 